\title{
Hypofyseapoplexie na gebruik van een gonadoreline (GnRH-)agonist
}

\author{
Femke M. Dessens ${ }^{1} \cdot$ Daniëlle Steenvoorden $^{2} \cdot$ Marieke van Oijen $^{1} \cdot$ Nienke R. Biermasz $^{1}$ \\ Catharina A. Goossens-Laan ${ }^{3}$
}

Published online: 15 November 2016

(C) The Author(s) 2016. This article is an open access publication.

Samenvatting Hypofyseapoplexie is een bloeding of infarct in de hypofyse en treedt meestal op in een hypofyseadenoom. De exacte pathofysiologie ervan is onbekend; wel wordt er een relatie met abnormale vasculatuur van een hypofyseadenoom beschreven. Het is een zeer zeldzame bijwerking van gonadoreline $(\mathrm{GnRH})$-agonisten. Wij beschrijven een 68-jarige man die een maand na toediening van gosereline, een $\mathrm{GnRH}$-agonist, progressieve hoofdpijn met diplopie ontwikkelde, met braken en een ptosis, met als vermoedelijke diagnose hypofyseapoplexie. Vanwege visusklachten kreeg patiënt een transsfenoïdale spoedresectie, waarna histologisch onderzoek de diagnose bevestigde.

Hypofyseapoplexie is een ernstige bijwerking van GnRH-agonisten, die kan optreden bij patiënten met een hypofyseadenoom. Bij hypopituïtarisme kan levenslange hormoonsubstitutie noodzakelijk zijn. Gezichtsvelduitval en visusverlies zijn redenen voor een spoedoperatie; waardoor frequente controle door de oogarts bij patiënten met hypofyseapoplexie belangrijk is.

Trefwoorden GnRH agonist gosereline • hypofyseapoplexie $\cdot$ hypofyseadenoom

drs. Femke M. Dessens

femkedessens@hotmail.com

1 afdeling Neurologie, Alrijne Ziekenhuis Leiderdorp, Leiderdorp, Nederland

2 afdeling Endocrinologie, Leids Universitair Medisch Centrum, Leiden, Nederland

3 afdeling Urologie, Alrijne Ziekenhuis Leiderdorp, Leiderdorp, Nederland

\section{Pituitary apoplexy as a side effect of gonadoreline (GnRH) agonists}

\begin{abstract}
Pituitary apoplexy is a bleeding or infarction in the pituitary gland and usually occurs in a pituitary adenoma. The exact pathophysiology is unknown, an abnormal vascularisation of the pituitary adenoma is described. Besides headache and cranial nerve palsy (n. oculomotorius, n. trochlearis, n. abducens and n. opticus), loss of consciousness, hypopituitarism and hyponatremia may occur. Pituitary apoplexy is a very rare side effect of gonadoreline $(\mathrm{GnRH})$ agonists.

We present a 68-year old man, who developed a progressive headache with diplopia, vomiting and a ptosis as a result of pituitary apoplexy a month after administration of gosereline, a GnRH-agonist. The patient underwent an urgent transsphenoidal resection because of visual disturbances, after which the histological investigation confirmed the diagnosis.

Pituitary apoplexy is a serious side effect of GnRH-agonists that can occur in patients with a pituitary adenoma. In case of hypopituitarism, a lifelong hormone substitution may be necessary. Visual field and vision loss are reasons for urgent surgical treatment, therefore frequent ophthalmological examinations are important in patients with a pituitary apoplexy.
\end{abstract}

Keywords GnRH agonist gosereline · Pituitary apoplexy • Pituitary adenoma

\section{Introductie}

Een bloeding of infarct dat optreedt in de hypofyse wordt hypofyseapoplexie genoemd. Dit is een zeer zeldzame aan- 

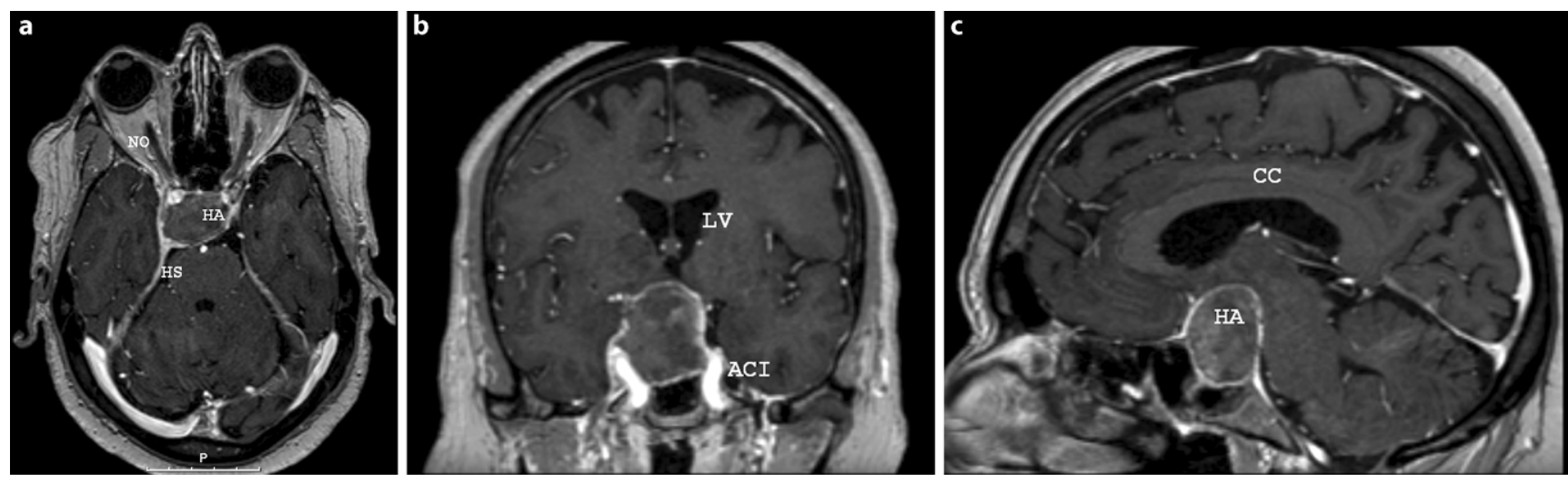

Figuur 1 MRI-scan van de hersenen met een in de sinus cavernosus doorgroeiend hypofyseadenoom. T1-gewogen opnamen met gadolinium. a Transversale doorsnede, b Coronale doorsnede, c Sagittale doorsnede. (HA hypofyseadenoom, $H S$ hersenstam, $N O$ nervus opticus, $C C$ corpus callosum, $A C I$ arteria carotis interna, $L V$ laterale ventrikel)

doening die meestal optreedt in een veelal nog niet gediagnosticeerd hypofyseadenoom. De eerste klachten bestaan vaak uit plotse hevige hoofdpijn, gezichtsvelduitval of diplopie, veroorzaakt door compressie van omliggende hersenzenuwen (n. oculomotorius, n. trochlearis, n. abducens en n. opticus). Er kan tevens bewustzijnsverlies, hypopituïtarisme en hyponatriëmie optreden. Hypofyseapoplexie wordt beschreven als een zeer zeldzame bijwerking van GnRH-agonisten.

Wij beschrijven een 68 -jarige patiënt met hypofyseapoplexie na gebruik van gosereline.

\section{Casus}

Patiënt A, een 68-jarige man, die bekend is met een ossaal gemetastaseerd prostaatcarcinoom, werd beoordeeld op de Spoedeisende Hulp (SEH) vanwege sinds één dag bestaande progressieve hoofdpijnklachten, misselijkheid met braken, diplopie en ptosis. Hij gebruikte sinds een maand gosereline, een GnRH-agonist, als vervanging van degarelix, een GnRH-antagonist, omdat gosereline minder frequent hoeft te worden toegediend.

$\mathrm{Bij}$ neurologisch onderzoek werd een pupilanisocorie gezien $(3 / 2 \mathrm{~mm}$, lichtreactie direct en indirect intact) met een ptosis en een abductie- en elevatiebeperking van het rechteroog, waaruit werd geconcludeerd dat er uitval bestond van de nervus (n.) oculomotorius en de $n$. abducens rechts. De MRI/MRA-scan van de hersenen (fig. 1) toonde een massa in de sella turcica met uitbreiding suprasellair en in de rechter sinus cavernosus, met compressie op het chiasma opticum, wat past bij een macroadenoom van de hypofyse. Gezien het acute begin van de klachten werd gedacht aan een hypofyseapoplexie.

De oogarts vond aanvankelijk geen aanwijzingen voor gezichtsvelduitval. Een macroprolactinoom werd uitgesloten, gezien het lage prolactinegehalte $(0,025 \mathrm{U} / \mathrm{l})$.
Overige hypofysehormonen toonden laag-normale uitslagen: vrij T4 (11,9 pmol/l), thyroïdstimulerend hormoon $(1,55 \mathrm{mU} / \mathrm{l})$, cortisol $(0,195 \mathrm{umol} / \mathrm{l})$, insulin-like growth factor-1 $(26,6 \mathrm{nmol} / \mathrm{l})$ en een verlaagd adrenocorticotroop hormoon $(\mathrm{ACTH})(<5 \mathrm{ng} / \mathrm{l})$. Het natriumgehalte was $141 \mathrm{mmol} / \mathrm{l}$. Het testosterongehalte was onmeetbaar laag, ten gevolge van het gebruik van gosereline. Vanwege corticosteroïdgebruik was de corticotrope as niet te beoordelen.

Vanwege toenemende sufheid bij koorts zonder focus werd preventief gestart met een hydrocortison stressschema, waarna hij opknapte. Bij herbeoordeling door de oogarts werden een uitval van het rechtergezichtsveld en een daling van de visus van het rechteroog gevonden, waarna hij met spoed een transsfenoïdale resectie onderging.

Histologisch onderzoek toonde een beeld dat past bij een apoplectisch adenoom met focale expressie van luteïniserend hormoon (LH), waarbij op het preparaat geen onderscheid gemaakt kon worden tussen een gonadotroop adenoom met focaliteit ten gevolge van necrose, dan wel een niet-functionerend adenoom met focale LH-expressie.

Direct postoperatief liet de corticotrope releasing hormone $(\mathrm{CRH})$ test onvoldoende stijging van het cortisol zien, waarop de hydrocortison gecontinueerd werd. Vanwege het hypogonadisme werd de medicamenteuze behandeling van het prostaatcarcinoom voorlopig gestaakt. Het postoperatieve beloop werd gecompliceerd door diabetes insipidus, liquorroe en door uitgebreide longembolieën. Vier maanden postoperatief was er afname van de ptosis, verbetering van de oogbewegingen en het gezichtsveld en bleef het PSA laag $(<0,05 \mathrm{ug} / \mathrm{L})$. De beslissing over het herstarten van gosereline bij stijging van het testosteron zal afhankelijk zijn van de aanwezigheid van een restadenoom op de MRI-scan. 


\section{Beschouwing}

Hypofyseapoplexie is een zeer zeldzame (1:15.000), maar zeer ernstige bijwerking van GnRH-agonisten en kan optreden bij patiënten met een vaak nog onbekend hypofyseadenoom. Hypofyseadenomen worden gevonden bij 6,1\% van de mensen bij autopsie, maar veel van deze tumoren zullen bij leven asymptomatisch en onontdekt blijven [1]. In de literatuur zijn, inclusief onze casus, 18 gevallen van hypofyseapoplexie na het gebruik van GnRH-agonisten beschreven, waarbij het interval tussen toediening van de GnRH-agonist en het optreden van hypofyseapoplexie varieerde van enkele minuten tot drie weken $[2,3]$.

\section{Hypofyseapoplexie}

Er zijn verschillende oorzaken voor het optreden van hypofyseapoplexie beschreven, zoals diabetes mellitus, verhoogde intracraniële druk en gebruik van anticoagulantia, oestrogenen en GnRH-agonisten [4]. De klachten bij presentatie zijn hoofdpijn, in combinatie met misselijkheid/ braken, ptosis, oftalmoplegie, verminderde visus, gezichtsvelduitval en pupilanisocorie als gevolg van de extrasellaire uitbreiding van het adenoom. Hiernaast kan ook bewustzijnsverlies optreden, meestal als gevolg van een Addisoncrisis. Bij dit laatste is snelle toediening van een hoge dosis hydrocortison noodzakelijk. Een zeldzamer oorzaak van bewustzijnsdaling is verhoogde intracraniële druk. Bij hypofyseapoplexie kan hypopituittarisme optreden en eerdere studies beschrijven het optreden van hyponatriëmie in $44 \%$ van de gevallen [5]. De hyponatriëmie kan veroorzaakt worden door hypocortisolisme, hypothyreoïdie, syndrome of inappropriate antidiuretic hormone of een combinatie hiervan [3].

De uitkomst van hypofyseapoplexie is variabel; er kan binnen een aantal maanden volledig herstel optreden, maar hypofyseapoplexie kan ook levensbedreigend zijn [2, 3]. Gezichtsvelduitval en visusverlies, door druk op het chiasma opticum, zijn indicaties voor een transsfenoïdale resectie. Indien mogelijk wordt gekozen voor een expectatief beleid [6]. Levenslange hormoonsubstitutie kan noodzakelijk zijn.

Histologisch onderzoek toonde bij alle beschreven casus een $\mathrm{LH}$ - of follikelstimulerend hormoon (FSH) producerend macroadenoom $[2,3]$.

\section{GnRH-agonisten}

Androgeendeprivatietherapie (ADT) is de therapie van eerste keuze bij gemetastaseerde prostaatkanker. GnRH-agonisten worden het meest gebruikt bij ADT en zijn synthetische analogen van het hypothalamushormoon gonadoreline (luteïniserend hormoon-'releasing' hormoon (LHRH)). Een synthetische GnRH-agonist is 100 keer zo sterk als een natuurlijk aanwezig GnRH [7]. GnRH-agonisten binden op de GnRH-receptoren op de gonadotropinesecernerende cellen van de hypofyse en zorgen voor forse stijging van $\mathrm{LH}$, FSH en testosteron. Deze stimulatie van de gonadotrofe cellen kan gerelateerd zijn aan het ontstaan van hypofyseapoplexie. De aanhoudende stimulatie van de hypofyse zorgt voor een downregulatie of verminderde sensitiviteit van de GnRH-receptor, met als gevolg verlaging van het hormoonniveau. Hierdoor daalt de testosteronspiegel bij de man na circa drie weken tot castratieniveau. Bij de vrouw dalen de oestrogeen- en progesteronspiegels en wordt de ovariumfunctie onderdrukt. Verlaging van de oestrogeenspiegel kan de groei van fibromyomen van de uterus en endometriosehaarden terugdringen, alsmede het endometrium doen slinken [8].

\section{Pathofysiologie}

Het exacte mechanisme van hypofyseapoplexie is onbekend. Een aannemelijke theorie voor het pathofysiologische mechanisme is die van de bifasische respons. De klachten in de acute fase zouden worden geïnitieerd doordat binnen 24 uur na stimulatie door de GnRH de hoeveelheid cytoplasma toeneemt, evenals het aantal secretoire LH-granules. Hierdoor ontstaat directe mechanische stress. In combinatie met de verhoogde metabole vraag en de al aanwezige veranderde bloedtoevoer en verzwakte capillairwanden in adenomen, ontstaat vervolgens ischemie. In de subacute fase zorgt stimulatie door GnRH-agonisten voor cellulaire groei van het adenoom, met een toegenomen metabole vraag en verhoogde intrasellaire druk [2, 4].

Er zijn ook patiënten beschreven met tekenen van verhoogde druk zonder bloeding na toediening van GnRHagonisten [9]. Met dit mechanisme is het goed verklaarbaar waarom hypofyseapoplexie nauwelijks optreedt bij GnRHantagonisten.

Opvallend is dat van de 18 eerdere casus, het slechts in één geval een vrouwelijke patiënt betreft; het is tot nog toe onduidelijk waarom hypofyseapoplexie vaker bij mannen optreedt [10].

Bij onze patiënt zit er een maand tussen de toediening van de GnRH-agonist en het ontstaan van de hypofyseapoplexie, later dan werd beschreven in eerdere casus. Er is één patiënt beschreven bij wie hypofyseapoplexie acht weken na subcutane implantatie van goserelineacetaat (GnRHagonist) optrad [11]. Een mogelijke verklaring van het verlate effect is dat de GnRH-agonist bij onze patiënt een persisterend stimulerend effect had op de groei van het hypofyseadenoom, zoals wordt beschreven bij enkele andere patiënten [12, 13]. Hiernaast was in onze casus de patiënt gewisseld van een GnRH-antagonist naar een -agonist. Door gebruik van GnRH-antagonisten ontstaat een down- 
regulatie van GnRH-receptoren en mogelijk een verhoogde opslag van gonadotropinen in de hypofyse. Toediening van een GnRH-agonist na eerdere behandeling met een antagonist zou kunnen leiden tot een vergroting en verlenging van het flare-upfenomeen [14].

\section{Conclusie}

Hypofyseapoplexie is een ernstige bijwerking van GnRHagonisten, die kan optreden bij patiënten met een bekend dan wel onbekend hypofyseadenoom. Naast hoofdpijn, braken en oftalmoplegie kan ook hypofysaire uitval ontstaan, met daarbij een levensbedreigend hypocortisolisme. Gezichtsvelduitval en visusverlies zijn redenen voor een spoedoperatie, waardoor frequente controle door de oogarts belangrijk is.

De uiteindelijke uitkomst van hypofyseapoplexie varieert. Het is een te zeldzame bijwerking om bij elke patiënt voorafgaand aan het gebruik van GnRH-agonisten een MRI-hersenen te maken. Bij een bekend niet-functionerend hypofyseadenoom raden wij aan de behandelopties in een multidisciplinair overleg te bespreken, waarbij gekozen kan worden voor een operatieve ingreep van het hypofyseadenoom, een orchidectomie of hormoontherapie. Indien therapie benodigd blijft na hypofyseapoplexie zijn de volgende opties beschikbaar: GnRH-antagonisten, gecontroleerd GnRH-agonisten bij een MRI-scan zonder restafwijkingen of bilaterale orchidectomie.

Open Access This article is distributed under the terms of the Creative Commons Attribution 4.0 International License (http:// creativecommons.org/licenses/by/4.0/), which permits unrestricted use, distribution, and reproduction in any medium, provided you give appropriate credit to the original author(s) and the source, provide a link to the Creative Commons license, and indicate if changes were made.

\section{Literatuur}

1. Davis A, Goel S, Picolos M, Wang M, Lavis V. Pituitary apoplexy after leuprolide. Pituitary. 2006;9:263-5.

2. Huang T, Lin J, Lieu A, Chen Y, Chen H, Jang M, et al. Pituitary apoplexy induced by Gonadotropin-releasing hormone agonists for treating prostate cancer-report of first Asian case. World J Surg Oncol. 2013;11:254-8.

3. Sasagawa Y, Tachibana O, Nakagawa A, Koya D, Lizuka H. Pituitary apoplexy following gonadotropin-releasing hormone agonist administration with gonadotropin-secreting pituitary adenoma. J Clin Neurosci. 2015;22:601-3.

4. Blaut K, Wisniewski P, Syrenicz A, Sworczak K. Apoplexy of clinically silent pituitary adenoma during prostate cancer treatment with LHRH analog. Neuro Endocrinol Lett. 2006;27:569-72.

5. Randeva HS, Schoebel J, Byrne J, Esiri M, Adams CB, Wass JA. Classical pituitary apoplexy: clinical features, management and outcome. Clin Endocrinol (Oxf). 1999;51:181-8.

6. Briet C, Salenave S, Chanson P. Pituitary apoplexy. Endocrinol Metab Clin North Am. 2015;44:199-209.

7. Ando S, Hoshino T, Mihara S. Pituitary apoplexy after goserelin. Lancet. 1995;345:458.

8. Shore ND, Abrahamsson PA, Anderson J, Crawford ED, Lange P. New considerations for ADT in advanced prostate cancer and the emerging role of GnRH antagonists. Prostate Cancer Prostatic Dis. 2013;16:7-15.

9. Guerra Y, Lacuesta E, Marquez F, Raksin PB, Utset M, Fogelfeld L. Apoplexy in non functioning pituitary adenoma after one dose of leuprolide as treatment for prostate cancer. Pituitary. 2010;13:54-9.

10. Engel G, Huston M, Oshima S, Beck C, Harsh G, Rosenthal MH, et al. Pituitary apoplexy after leuprolide injection for ovum donation. J Adolesc Health. 2003;32:89-93.

11. Sinnadurai M, Cherukuri RK, Moses RG, Nasser E. Delayed pituitary apoplexy in patient with advanced prostate cancer treated with gonadotrophin-releasing hormone agonists. J Clin Neurosci. 2010;17:1201-3.

12. Sassolas G, Lejeune H, Trouillas J, Forest MG, Claustrat B, Lahlou $\mathrm{N}$, et al. Gonadotropin-releasing hormone agonists are unsuccessful in reducing tumoral gonadotropin secretion in two patients with gonadotropin-secreting pituitary adenomas. J Clin Endocrinol Metab. 1988;67:180-5.

13. Schuval BJ, Kirschenbaum A, Wolfe D, Post KD, Levine AC. Lack of effect of a gonadotropin-releasing hormone agonist in a patient with prostate cancer and a gonadotroph adenoma. J Clin Endocrinol Metab. 1996;81:864.

14. Taylor JE, Miller BT, Gray KD, Scott RT, Catherino WH, Segars $\mathrm{JH}$. The mechanism responsible for the supraphysiologic gonadotropin surge in GnRH-agonist-treated, GnRH-antagonist-primed females. Fertil Steril. 2010;93:1668-75.

drs. Femke M. Dessens anios neurologie

drs. Daniëlle Steenvoorden aios interne geneeskunde

dr. Marieke van Oijen neuroloog

dr. Nienke R. Biermasz internist-endocrinoloog

dr. Catharina A. Goossens-Laan uroloog 